\title{
Study on Hygroscopic Swelling and Dehumidification Cracking Characteristics of Expansive Soil under Acid Rain and Cyclic Drying-Wetting
}

\author{
Jin Chang, ${ }^{1,2,3}$ Jie Xiao $\mathbb{D}^{\mathrm{D}},{ }^{2}$ Jian-Qing Jiang, ${ }^{1}$ Rui Zhang, ${ }^{1}$ Xi-Long Kuang, ${ }^{1}$ Ming Lei, ${ }^{1}$ \\ and He-Ping Yang ${ }^{2}$ \\ ${ }^{1}$ College of Civil Engineering, Changsha University, Changsha 410022, China \\ ${ }^{2}$ School of Traffic and Transportation Engineering, Changsha University of Science \& Technology, Changsha 410114, China \\ ${ }^{3}$ School of Naval Architecture, Ocean and Civil Engineering, Shanghai Jiaotong University, Shanghai 200030, China \\ Correspondence should be addressed to Jie Xiao; xiaojie324@csust.edu.cn
}

Received 21 August 2020; Revised 7 November 2020; Accepted 28 February 2021; Published 27 March 2021

Academic Editor: Jian Ji

Copyright (c) 2021 Jin Chang et al. This is an open access article distributed under the Creative Commons Attribution License, which permits unrestricted use, distribution, and reproduction in any medium, provided the original work is properly cited.

In this study, to reveal the swelling and cracking characteristics of expansive soil subjected to cyclic drying-wetting of acid rain, the effects of acid rain and cyclic drying-wetting on the swelling deformation of expansive soil were studied by using the load-free swelling rate test. Afterward, a high-definition digital camera was used to capture the crack development images of the sample during the dehumidification process under cyclic drying-wetting of acid rain. Furthermore, the changes of the microstructure and mineral composition of the expansive soil after cyclic drying-wetting of acid rain were analyzed by using the scanning electron microscopy (SEM) and X-ray diffraction (XRD) tests. Finally, the effect mechanisms of acid rain and cyclic drying-wetting on the swelling deformation and crack development of the expansive soil were discussed. The results indicate that acid rain has a positive effect on the swelling deformation and crack development of the expansive soil. The effect is greater with a stronger acidity of rainfall. Moreover, the combined action of acid rain and cyclic drying-wetting can promote the swelling deformation and crack development of the sample more notably. The swelling rate of the sample increased most significantly during the first two-time cyclic drying-wetting. The measured swelling rates at $\mathrm{pH}=3$ and 5 are $23.7 \%$ and $20.6 \%$, respectively, which are higher than the swelling rates of $19.0 \%$ at $\mathrm{pH}=7$. The humidity of samples is $17-18 \%$ after the first-time drying-wetting cycle. The crack area ratios $\left(M_{f}\right)$ of the samples with $\mathrm{pH}$ values of 5 and 3 are, respectively, increased by $11.0 \%$ and $69.1 \%$; the average crack width of the sample increases by $32.3 \%$ and $93.3 \%$, respectively, compared with pH values of 7 . After the fourth-time drying-wetting cycle, $M_{f}$ and the average crack width of the samples under the rainwater environment of three $\mathrm{pH}$ values increase greatly, but the difference of $M_{f}$ among them became unapparent. In addition, the microscopic test results show that acid rain can corrode the binding materials (e.g., $\mathrm{SiO}_{2}, \mathrm{Al}_{2} \mathrm{O}_{3}, \mathrm{~K}_{2} \mathrm{O}, \mathrm{MgO}$, and $\mathrm{CaO}$ ) in the expansive soil. The erosion of the binding minerals weakens the structural connection strength, resulting in continuous increases in both size and number of microvoids. Under the superimposed influence of cyclic drying-wetting, the above changes are even more dramatic. Macroscopically, the swelling deformation of expansive soil increases and the cracks develop rapidly.

\section{Introduction}

The expansive soil, which is very sensitive to cyclic dryingwetting of atmospheric environment, shows the characteristics of strong water absorption swelling and water loss shrinkage or cracking. Existing research on expansive soil [1-5] shows that the emergence and development of inner crack is one of the main reasons for frequent slope instability. In addition, the cyclic drying-wetting of the atmospheric environment further aggravates the development of a crack in soil, which accelerates the destruction of soil structure and facilitates the infiltration of rainwater. The shallow soil of the slope expands unevenly after moisture absorption, which easily leads to local shear dislocation and collapse. 
Rainfall is one of the main reasons for soil slope landslides. Meanwhile, acid rain is increasing commonly with the worsening of the environment. The effect of acid rain on the landslides may be more complicated than that of the conventional rain. It is not only affected by the pore water pressure but also affected by the mineral composition and structure of soil [6-8]. Several studies on the physical and mechanical properties and microstructure of soil under acid rain environment have been conducted during the past decades.

The existing research results show that the acidic dry-wet cycle not only aggravates the strength deterioration of sandstone $[9,10]$ but also increases the expansibility of montmorillonite due to cation exchange and mineral dissolution [11]. Besides, acid rain would accelerate the precipitation of calcium ions in light soil and increase soil permeability [12]. As a result, the acid rain would destroy the soil structure, causing the loss of metal ions such as iron and aluminum from the soil matrix $[13,14]$. The lower the $\mathrm{pH}$ value of infiltration acid rain, the greater the compressibility of the soil. In addition, the shear strength decreased with the decrease of the $\mathrm{pH}$ value of acid rain based on physical and mechanical property tests of primary and secondary kaolin under acid rain infiltration [15]. The physical and mechanical properties test of composite fine-grained soil under acid rain showed that the unconfined compressive strength and shear strength of the composite fine-grained soil decreased with the decrease of the $\mathrm{pH}$ value of acid rain [16]. In addition, acid rain could decrease the concentration of exchangeable cations in soil, resulting in the decrease of internal force and stability of soil structure. Zhu [17] also found that acid rain would reduce the shear strength of red clay within 3 meters of the land surface. Chang et al. [18] found that acid rain will reduce the shear strength of expansive soil. The smaller the rainwater $\mathrm{pH}$ value, the more obvious the decrease of soil strength.

In conclusion, acid rain erosion changes the microstructure and mineral composition of rock and soil, resulting in degradation of the macroperformance of rock and soil and adverse effects on the project.

In Baise area of the Guangxi Zhuang Autonomous Region, the widely distributed expansive soil is affected significantly by the acid rain. From 2003 to 2015, a survey on the acid rain in this area showed that the lowest $\mathrm{pH}$ value of the rainfall was 2.32, and the frequency of acid rain was $67.2 \%[19,20]$. Numerous cracks were found in the shallow soil of expansive soil slope under the action of the cyclic drying-wetting atmosphere, which provides a convenient channel for acid rain infiltration. It is well known that the hygroscopic swelling and dehumidification cracking are the basic characteristics of expansive soil. These characteristics are also the key factors affecting the stability of expansive soil slope, although several experimental studies have been carried out on the physical and mechanical properties of expansive soil under acid rain environment. However, the coupling effects of acid rain and cyclic drying-wetting on moisture absorption expansion and dehumidification cracking of expansive soil are still unclear. It is helpful to reveal the causes of shallow instability of expansive soil cutting slope in the acid rain area.

This paper aims to investigate the effect of acid rain and cyclic drying-wetting on the expansive soil in Baise, Guangxi Zhuang Autonomous Region. This paper is arranged as follows: first, the rule of moisture absorption expansion and dehumidification cracking of expansive soil were studied based on the swelling rate test and fracture observation test under acid rain and cyclic drying-wetting. Then, the microstructure and chemical composition evolution of the samples were investigated by the SEM and XRD methods. Finally, the effect of acid rain and cyclic drying-wetting on the swelling deformation and crack development of the expansive soil were discussed based on the observed results.

\section{Materials and Methods}

\subsection{Test Soil. Table 1 shows the properties of the soil.}

2.2. Preparation of Acid Solutions. Previous studies have shown that the type of acid rain found in China is dominated by sulfuric acid, and the ratio of the sulfate radical relative to the nitrate ion is close to $3: 1$ [21]. Therefore, in this experiment, the dilute sulfuric acid and the dilute nitric acid with a molar ratio of $\mathrm{SO}_{2}{ }^{2-}: \mathrm{NO}_{3}{ }^{-}=3: 1$ were used to prepare the acid solutions [21]. According to the acid rain statistics from the Baise area, two typical $\mathrm{pH}$ values of 3 and 5 were obtained for the acid solutions $[19,20]$. In addition, a neutral distilled water solution with a $\mathrm{pH}$ value of 7 was used as the control group. The prepared $\mathrm{pH}$ solution was placed in stainless steel barrel for sealed storage, and the stainless steel barrel was placed in a dark place.

2.3. Cyclic Drying-Wetting Test. Sample saturation method: a standard ring cutter sample with a diameter of $61.8 \mathrm{~mm}$ and height of $20 \mathrm{~mm}$ was made by cutting the undisturbed soil. A piece of filter paper and a permeable stone were placed successively on the top and bottom sides of the sample. Thereafter, the sample was put into the overlapping saturator (as shown in Figure 1). The overlapping saturator was put into the vacuum saturation tank with acid solution. The $\mathrm{pH}$ value of the acid solution was set as 3, 5, and 7, respectively (as shown in Figure 2). The vacuum is saturated for 24 hours. A saturation test was completed by immersing the sample into the corresponding acid solution for one week so that the solution fully reacts with the soil.

Sample dehumidification method: first, the saturated sample was taken out from the saturated cylinder. Then, the saturator device was unloaded from the sample. Thereafter, the sample was dehumidified by putting it into a $50^{\circ} \mathrm{C}$ constant temperature box (as shown in Figure 3). The dehumidification test was completed after stable shrinkage of the sample.

The one to four-time cyclic drying-wetting tests were conducted, respectively, by repeating the above sample saturation and dehumidification operations. 
TABLe 1: Characteristic index of expansive soil.

\begin{tabular}{|c|c|c|c|c|c|c|c|c|c|c|}
\hline \multirow{2}{*}{ Soil name } & \multirow{2}{*}{$\begin{array}{l}\text { Proportion } \\
\quad\left(G_{s}\right)\end{array}$} & \multirow{2}{*}{$\begin{array}{c}\text { Natural } \\
\text { moisture } \\
\text { content } \\
w(\%)\end{array}$} & \multirow{2}{*}{$\begin{array}{l}\text { Liquid } \\
\text { limit } \\
w_{L}(\%)\end{array}$} & \multirow{2}{*}{$\begin{array}{l}\text { Plastic } \\
\text { limit } \\
w_{\mathrm{p}}(\%)\end{array}$} & \multirow{2}{*}{$\begin{array}{c}\text { Plasticity } \\
\text { index } \\
I_{\mathrm{P}}\end{array}$} & \multicolumn{3}{|c|}{ Particle composition/\% } & \multirow{2}{*}{$\begin{array}{c}\text { Montmorillonite } \\
\text { content }(\%)\end{array}$} & \multirow{2}{*}{$\begin{array}{c}\text { Free } \\
\text { expansion } \\
\text { rate } \delta_{\text {ef }}(\%)\end{array}$} \\
\hline & & & & & & $>0.075 \mathrm{~mm}$ & $\begin{array}{c}0.005 \\
\mathrm{~mm}\end{array}$ & $<0.005 \mathrm{~mm}$ & & \\
\hline $\begin{array}{l}\text { Baise } \\
\text { expansive } \\
\text { soil }\end{array}$ & 2.7 & 20.6 & 56.26 & 21.37 & 34.89 & 0.10 & 52.02 & 47.88 & 16.58 & 82 \\
\hline
\end{tabular}

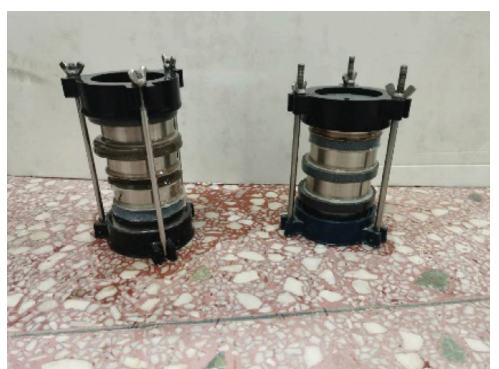

FIgURE 1: Overlapping saturator.

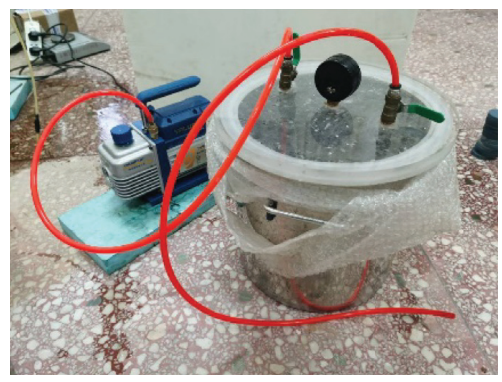

Figure 2: Vacuum saturation.

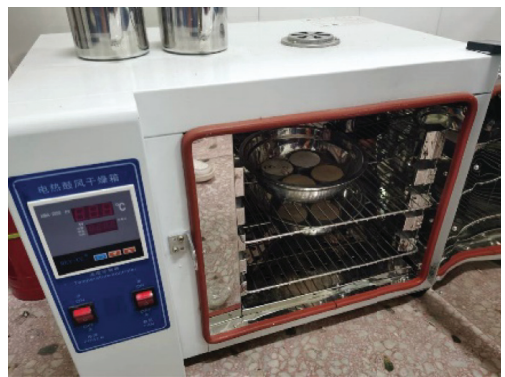

FIgUre 3: Constant temperature oven.

2.4. Swelling Rate Test. The samples that have completed the saturation test in solutions with $\mathrm{pH}$ values of 3,5 , and 7 are taken out and placed in a soil dilatometer to perform unloaded expansion tests under the action of cyclic dryingwetting one to four times, respectively.

2.5. Crack Observation Test. After the saturation test with $\mathrm{pH}$ values of 3,5 , and 7 , the samples were dehumidified in a box with a constant temperature of $50^{\circ} \mathrm{C}$. The moisture content was recorded in time. The crack on the dehumidified specimen was observed and measured with a high-definition digital camera for the one to four-time cyclic drying-wetting, respectively.

\section{Results and Discussion}

3.1. The Effect of Acid Rain and Cyclic Drying-Wetting on Sample Swelling Rate. The swelling rate of the sample under the interaction of acid rain and cyclic drying-wetting is shown in Figure 4.

As shown in Figure 4, after one-time cyclic dryingwetting, the swelling rate of expansive soil increased with the decrease of the $\mathrm{pH}$ value of rainwater. When the $\mathrm{pH}$ value dropped from 7 to 5 and 7 to 3 , the swelling rate increased by $6.4 \%$ and $24.4 \%$, respectively. This result shows that the stronger the acidity of the rain, the more severe the swelling of the sample. In addition, Figure 4 shows that the swelling rate of the sample under different $\mathrm{pH}$ value solutions increases first and then gradually stabilizes with the increase of the cyclic drying-wetting. The smaller the solution $\mathrm{pH}$ value, the greater the swelling rate. The swelling rate of the sample increased the most after the first two times cyclic dryingwetting. The swelling rates at $\mathrm{pH}$ values of 3 and 5 were $23.7 \%$ and $20.6 \%$, respectively, which were $24.7 \%$ and $7.9 \%$ higher than the $19.0 \%$ at a $\mathrm{pH}$ value of 7 .

3.2. Analysis on the Influence of Acid Rain and Cyclic DryingWetting Factors on Swelling Deformation. As shown in Table 2 , when the $\mathrm{pH}$ value of the solution dropped from 7 to 3 , the swelling rate of the sample after one-time cyclic drying-wetting increases by $24.4 \%$. When the cyclic drying-wetting increases 4 times, the swelling rate of the sample in rainwater with a $\mathrm{pH}$ value of 7 increases by $25.6 \%$. Considering the combined effect of acid rain cyclic drying-wetting, the swelling rate of the samples with a $\mathrm{pH}$ value of 3 acid rain and four-time cyclic dryingwetting increased by $57.1 \%$ as compared with the sample with a $\mathrm{pH}$ value of 7 neutral water and one-time cyclic drying-wetting. This result shows that acid rain, cyclic drying-wetting, and their combined effect promote the swelling deformation of expansive soil. Among them, the combined effect of acid rain and cyclic drying-wetting promotes the most.

3.3. Cracks of Samples during Different Humidity under the Influence of Acid Rain and Cyclic Drying-Wetting. Here, the photos of the crack development during the dehumidification process under the interaction of acid rain ( $\mathrm{pH}$ value of 


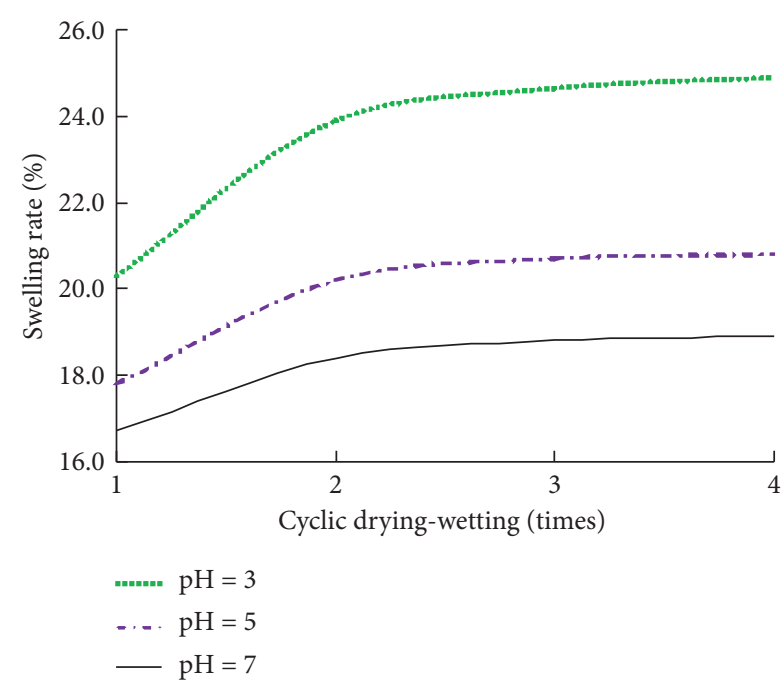

FIGURE 4: Swelling rate of the sample under acid rain and cyclic drying-wetting.

TABle 2: The expansion rate of the sample under different conditions.

\begin{tabular}{|c|c|c|c|}
\hline \multirow[b]{2}{*}{$\begin{array}{l}\text { Cyclic drying-wetting/ } \\
\text { times }\end{array}$} & \multicolumn{3}{|c|}{ Swelling rate $(\%)$} \\
\hline & $\mathrm{pH}=3$ & $\mathrm{pH}=7$ & $\begin{array}{c}\text { Difference between the } \\
\text { two }\end{array}$ \\
\hline 1 & 19.4 & 15.6 & 3.8 \\
\hline 4 & 24.5 & 19.6 & 4.9 \\
\hline Growth rate & $26.3 \%$ & $25.6 \%$ & $28.9 \%$ \\
\hline
\end{tabular}

3,5 , and 7) and cyclic drying-wetting (one and four times) are shown in Figures 5 and 6, respectively.

Figure 5 shows that the crack of the sample for the three $\mathrm{pH}$ values increases sharply with the decrease of sample humidity. In one-time cyclic drying-wetting, with a further decrease of sample humidity, the growth rates of crack length and width gradually decrease due to shrinkage deformation of the sample. In addition, it can also be seen from Figure 5 that the effect of acid rain on the development of crack depends on the $\mathrm{pH}$ value. The decrease of the $\mathrm{pH}$ value promotes crack development. Comparative between Figures 5 and 6 shows that the crack increased significantly for all the three $\mathrm{pH}$ values when the cyclic drying-wetting increased to four times. This phenomenon indicates that the interaction of acid rain and cyclic drying-wetting promotes the crack development more significantly.

\subsection{The Crack Area Ratio of Samples during Dehumidification} Process under the Influence of Acid Rain and Cyclic DryingWetting. The influence of acid rain and cyclic drying-wetting on the crack development of the expansive soil samples was quantitatively analyzed by the IPP (Image-Pro Plus) image-processing software. The crack characteristic parameters in the photos of the samples were thus obtained under the interaction of acid rain and cyclic drying-wetting. The crack area ratio and the average crack width during the dehumidification process under the interaction of acid rain
( $\mathrm{pH}$ value of 3,5 , and 7) and cyclic drying-wetting (one and four times) are shown in Tables 3-6, respectively.

According to the data of the samples in Tables 3 and 4, the relationship between the crack area ratio and moisture content during the dehumidification is shown in Figure 7. The surface crack area ratio can be expressed as

$$
M_{f}=\sum_{i=1}^{N} \frac{A_{i}}{A_{w}}
$$

where $M_{f}$ is the crack area ratio; $A_{w}$ is the area of the sample with humidity at $w ; A_{i}$ is the area of the $i$ th crack; and $N$ is the total number of cracks in the sample.

As shown in Figure 7, $M_{f}$ of the sample increases first and then decreases with the decrease of humidity for the $\mathrm{pH}$ values of 3, 5, and 7. Each dehumidification process has a peak value, when the sample dehumidification exceeds the corresponding peak humidity, it gradually decreases. The smaller the $\mathrm{pH}$ value, the greater the $M_{f}$. After one-time cyclic drying-wetting, when the humidity of the sample is $17-18 \%$ and the $\mathrm{pH}$ value of the solution is 5 and $3, M_{f}$ of the sample increases by $11.0 \%$ and $69.1 \%$, respectively, compared with the $\mathrm{pH}$ value of 7 . When the humidity is reduced to $8-9 \%, M_{f}$ of the acid solution with a pH value of 5 and 3 is $35.3 \%$ and $93.8 \%$ higher than that of the sample with $\mathrm{pH} 7$, respectively. For the four-time cyclic drying-wetting, $M_{f}$ of the sample increases for all the three $\mathrm{pH}$ values. The differences among the three curves decrease.

As shown in Figure 8, the variation of the average crack width of the sample with water content is the same as that of $M_{f}$ mentioned above. After one-time cyclic drying-wetting, when the humidity of the sample is $17-18 \%$ and the $\mathrm{pH}$ value of the solution is 5 and 3, the average crack width of the sample increases by $32.3 \%$ and $93.3 \%$, respectively, compared with the $\mathrm{pH}$ value of 7 . When the humidity is reduced to $8-9 \%$, the average crack width of the acid solution with a $\mathrm{pH}$ value of 5 and 3 is $39.1 \%$ and $118.8 \%$ higher than that of the sample with $\mathrm{pH} 7$, respectively. For the four-time cyclic drying-wetting, when the humidity of the sample is $15-16 \%$ and the $\mathrm{pH}$ value of the solution is 5 and 3 , the average crack width of the sample increases by $14.1 \%$ and $29.2 \%$, respectively, compared with the $\mathrm{pH}$ value of 7 .

3.5. Microstructure Characteristics of Expansive Soil under Acid Rain and Cyclic Drying-Wetting. The eroded surfaces of the samples after one- and four-time cyclic drying-wetting $(\mathrm{pH}=3,5$, and 7$)$ were dehumidified by vacuum freezedrying method [22], and then SEM and XRD tests were carried out.

3.5.1. SEM Image Analysis. The SEM test results of the samples under the influence of acid rain ( $\mathrm{pH}$ value of 3,5 , and 7) and cyclic drying-wetting (one and four times) are shown in Figures 9 and 10.

Figure 9 shows that there are lamellar microstructure units in the microstructure of Baise expansive soil, which are arranged in surface-to-surface contact. After one-time cyclic drying-wetting, with the $\mathrm{pH}$ value of the rainwater decreases, 


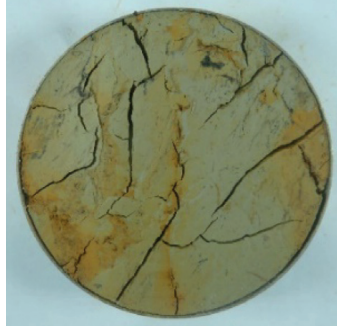

$18 \%$

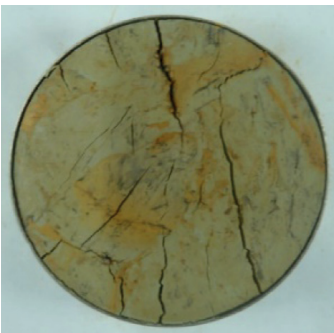

$18 \%$

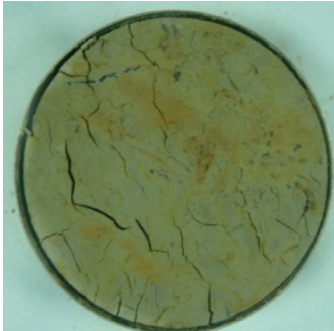

$17 \%$

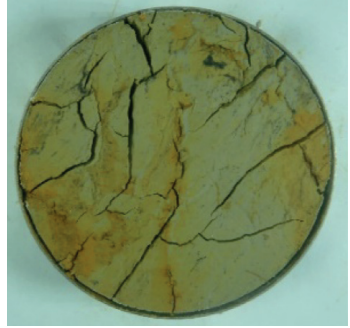

$14 \%$

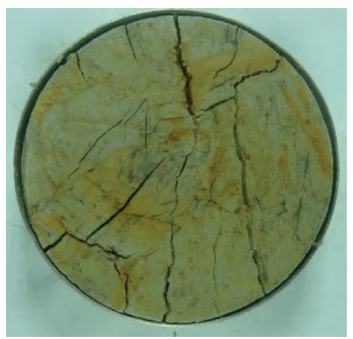

$14 \%$

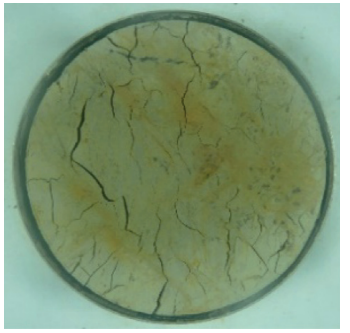

$12 \%$

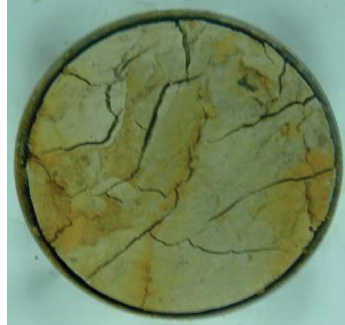

$9 \%$

(a)

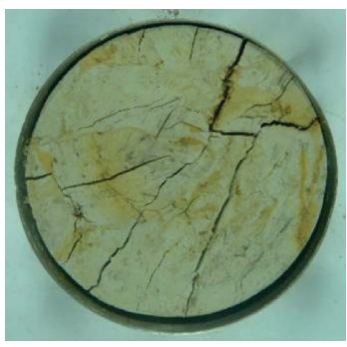

$9 \%$

(b)

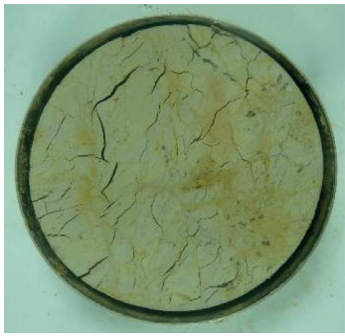

$8 \%$

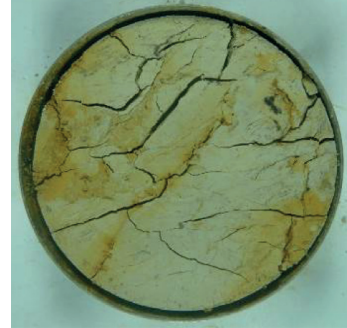

$6 \%$

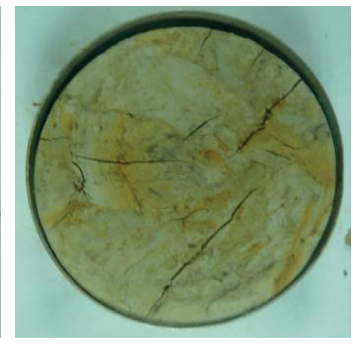

$6 \%$

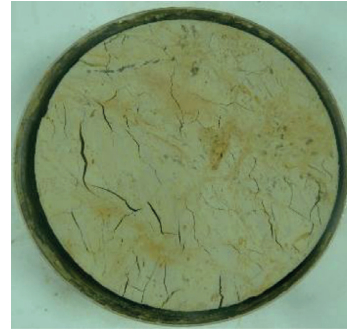

$4 \%$

(c)

FIGURE 5: Crack development of sample with different humidity after one-time cyclic drying-wetting. (a) $\mathrm{pH}=3$, (b) $\mathrm{pH}=5$, and (c) $\mathrm{pH}=7$.

the micropores of the soil continue to develop, the pore volume continues to increase, and the edges of the laminated structure gradually open. After four-time cyclic dryingwetting, under the action of acid rain, the size of pores in soil microstructure increases and their arrangement tends to be disordered (as shown in Figure 10). With the decrease of the $\mathrm{pH}$ value of rainwater, the size and distribution range of micropores in the soil are further increased, and some parts are connected with each other to form connected pores.

3.5.2. Analysis of XRD Test Results. The XRD test results of samples under the influence of acid rain ( $\mathrm{pH}$ value of 3,5 , and 7) and cyclic drying-wetting (one and four times) are shown in Table 7.

As shown in Table 7, the main chemical components of Baise expansive soil are $\mathrm{SiO}_{2}, \mathrm{Al}_{2} \mathrm{O}_{3}, \mathrm{CaO}, \mathrm{Fe}_{2} \mathrm{O}_{3}$, and $\mathrm{K}_{2} \mathrm{O}$, in which $\mathrm{SiO}_{2}$ and $\mathrm{Al}_{2} \mathrm{O}_{3}$ account for a large proportion, which are the main materials constituting the skeleton structure of the basic mineral unit of expansive soil.

After one-time cyclic drying-wetting, with the decrease of the $\mathrm{pH}$ value of acid rain, the quality of $\mathrm{CaO}, \mathrm{Fe}_{2} \mathrm{O}_{3}$, and $\mathrm{K}_{2} \mathrm{O}$ decreased in varying degrees. When the $\mathrm{pH}$ value of acid rain changes from 7 to 3 , the mass of oxides such as $\mathrm{CaO}, \mathrm{Fe}_{2} \mathrm{O}_{3}$, and $\mathrm{K}_{2} \mathrm{O}$ decreased from $10.27 \%, 7.31 \%$, and $3.19 \%$ to $5.74 \%, 5.02 \%$, and 2.22\%, respectively. After four-time cyclic drying-wetting, the quality of these oxides continues to decline. Wang and Siu [23] studies show that, under the action of acid rain, the crystallinity of clay minerals of expansive soil becomes worse, and the free cement such as $\mathrm{SiO}_{2}, \mathrm{Al}_{2} \mathrm{O}_{3}, \mathrm{~K}_{2} \mathrm{O}, \mathrm{MgO}$, and $\mathrm{CaO}$ is all dissolved in different degrees. Moreover, Table 4 shows that the corrosion amount of $\mathrm{CaO}, \mathrm{Fe}_{2} \mathrm{O}_{3}, \mathrm{~K}_{2} \mathrm{O}$, and other oxides in the sample under the action of acid rain is significantly greater than that of $\mathrm{SiO}_{2}$ and $\mathrm{Al}_{2} \mathrm{O}_{3}$, and the dissolution amount continues to increase after one-time cyclic drying-wetting.

3.6. The Effect Mechanisms of Acid Rain and Cyclic DryingWetting on the Swelling Deformation and Crack Development of the Expansive Soil. Based on the test results of SEM and XRD of Baise expansive soil under the influence of acid rain and cyclic drying-wetting, the structural diagram of the structure of surface-to-surface contact microstructure units of Baise expansive soil was drawn, as shown in Figure 11.

3.6.1. The Influence Mechanism of Acid Rain and Cyclic Drying-Wetting on Swelling Deformation of Expansive Soil. The results of SEM and XRD tests show that free $\mathrm{SiO}_{2}, \mathrm{Al}_{2} \mathrm{O}_{3}$, $\mathrm{K} \cdot \mathrm{O}, \mathrm{MgO}$, and $\mathrm{CaO}$ in expansive soil are corroded and leached under the influence mechanism of acid rain. The 


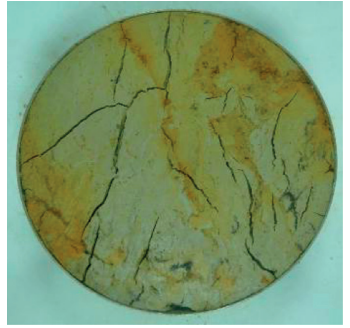

$19 \%$

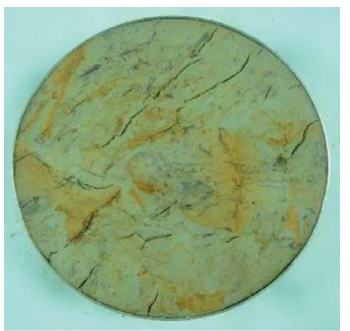

$21 \%$

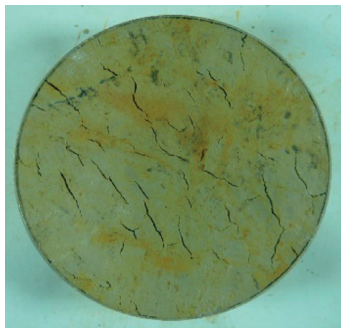

$20 \%$

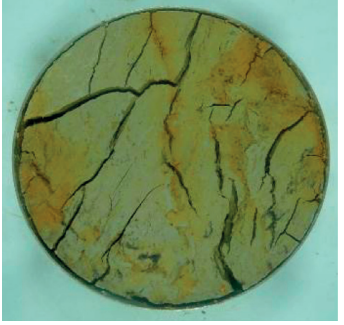

$16 \%$

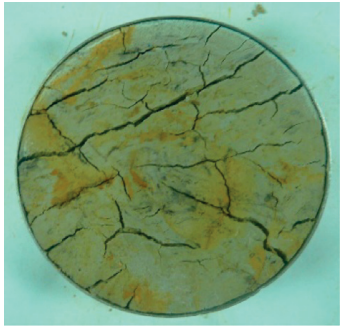

$17 \%$

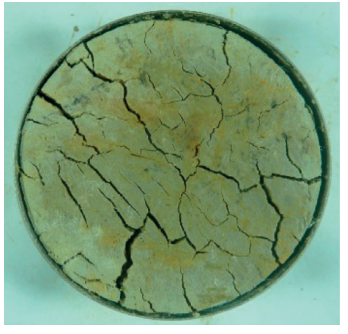

$15 \%$

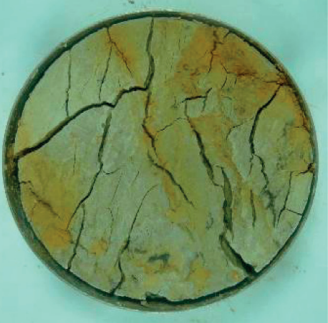

$11 \%$

(a)

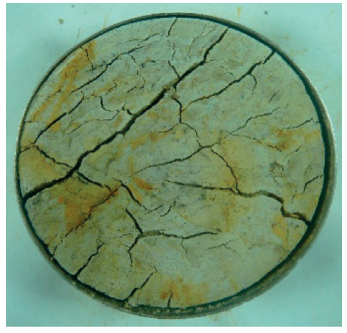

$11 \%$

(b)

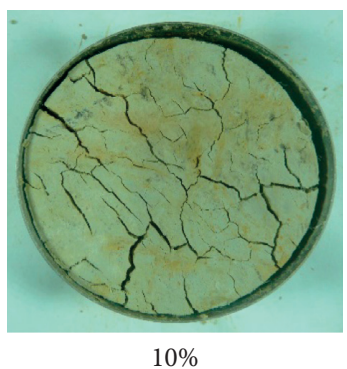

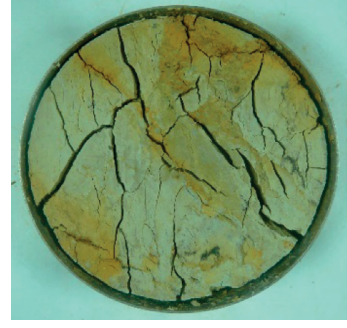

$8 \%$

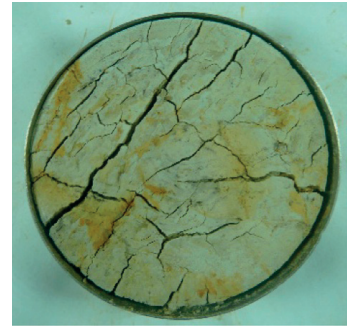

$8 \%$

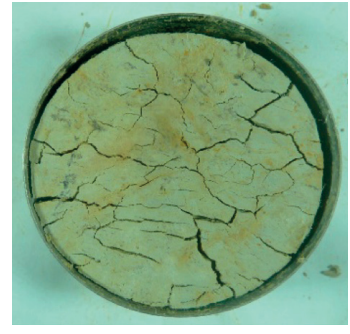

$7 \%$

(c)

FIGURE 6: Crack development of sample with different humidity after four-time cyclic drying-wetting. (a) $\mathrm{pH}=3$, (b) $\mathrm{pH}=5$, and (c) $\mathrm{pH}=7$.

TABLE 3: The crack area ratio $\left(M_{f}\right)$ of the sample after one-time cyclic drying-wetting.

\begin{tabular}{|c|c|c|c|c|c|}
\hline \multirow{3}{*}{$\mathrm{pH}$ value } & \multicolumn{5}{|c|}{$M_{f}(\%)$} \\
\hline & \multicolumn{5}{|c|}{ Humidity } \\
\hline & $22 \%$ & $17-18 \%$ & $12-14 \%$ & $8-9 \%$ & $4-6 \%$ \\
\hline 3 & 0.00 & 4.65 & 5.01 & 4.12 & 3.81 \\
\hline 5 & 0.00 & 3.01 & 3.58 & 2.91 & 2.40 \\
\hline 7 & 0.00 & 2.75 & 2.89 & 2.15 & 1.90 \\
\hline
\end{tabular}

TABLE 4: The crack area ratio of the sample under four-time cyclic drying-wetting.

\begin{tabular}{lccccc}
\hline pH value & \multicolumn{5}{c}{$M_{f}(\%)$} \\
Humidity \\
& $22 \%$ & $19-21 \%$ & $15-16 \%$ & $10-11 \%$ & $7-8 \%$ \\
\hline 3 & 0.00 & & 6.54 & 6.72 & 6.33 \\
5 & 0.00 & 4.41 & 5.85 & 6.01 & 5.58 \\
7 & 0.00 & 2.29 & 5.38 & 5.01 & 4.67 \\
\hline
\end{tabular}

stronger the acidity of rainwater, the greater the erosion degree, which may lead to the reduction of soil cementation. In addition, under the action of cyclic drying-wetting, the soil may repeatedly swell and shrink, which promotes the development of micropores and creates more favorable
TABle 5: The average crack width of the sample after one-time cyclic drying-wetting.

\begin{tabular}{lccccc}
\hline \multirow{3}{*}{ pH value } & \multicolumn{5}{c}{ Average crack width $(\mathrm{mm})$} \\
& $22 \%$ & $17-18 \%$ & $12-14 \%$ & $8-9 \%$ & $4-6 \%$ \\
\hline 3 & 0.00 & 1.74 & 1.98 & 1.40 & 1.13 \\
5 & 0.00 & 1.19 & 1.46 & 0.89 & 0.75 \\
7 & 0.00 & 0.90 & 1.15 & 0.64 & 0.54 \\
\hline
\end{tabular}

TABLE 6: The average crack width of the sample under four-time cyclic drying-wetting.

\begin{tabular}{lccccc}
\hline \multirow{3}{*}{ pH value } & \multicolumn{5}{c}{ Average crack width (mm) } \\
& & \multicolumn{5}{c}{$\begin{array}{c}\text { Humidity } \\
\end{array}$} & $22 \%$ & $19-21 \%$ & $15-16 \%$ & $10-11 \%$ & $7-8 \%$ \\
\hline 3 & 0.00 & 1.91 & 2.48 & 2.27 & 1.99 \\
5 & 0.00 & 1.71 & 2.19 & 2.04 & 1.79 \\
7 & 0.00 & 1.66 & 2.02 & 1.81 & 1.41 \\
\hline
\end{tabular}

conditions for the infiltration of acid rain. As shown in Figure 11, the surface-to-surface contact microstructure unit was expanded gradually, which promotes the development of pores and eventually leads to the increase of soil swelling deformation. 


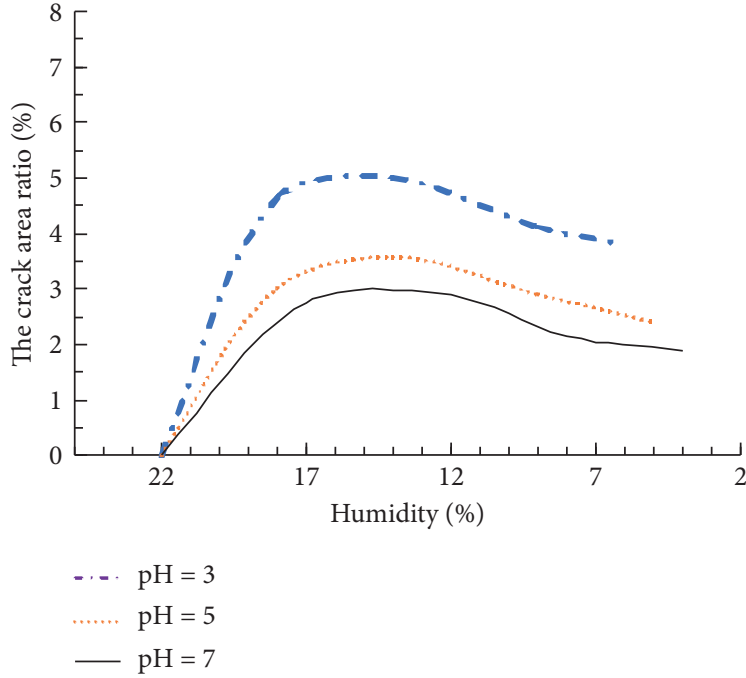

(a)

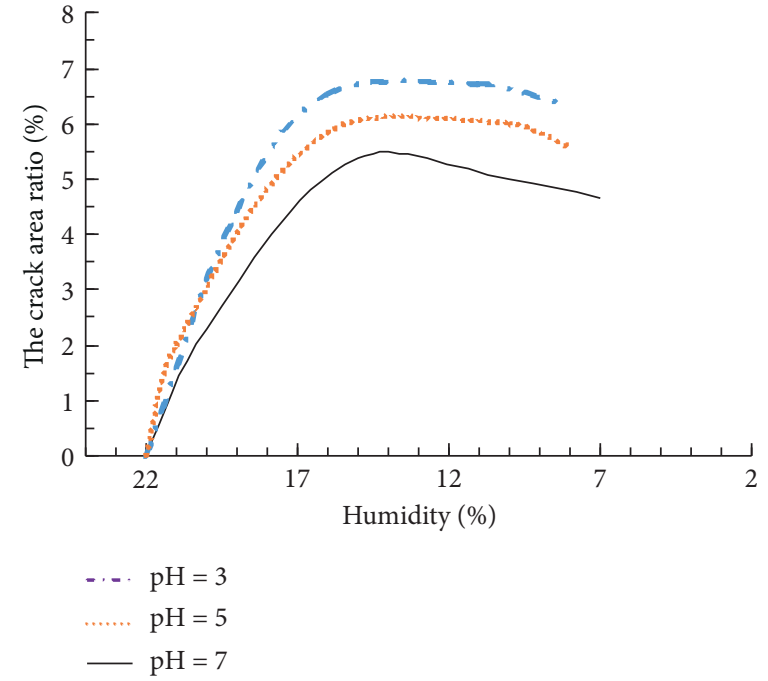

(b)

FIGURE 7: The crack area ratio under cyclic drying-wetting samples during the dehumidification process. (a) One-time cyclic drying-wetting. (b) Four-time cyclic drying-wetting.

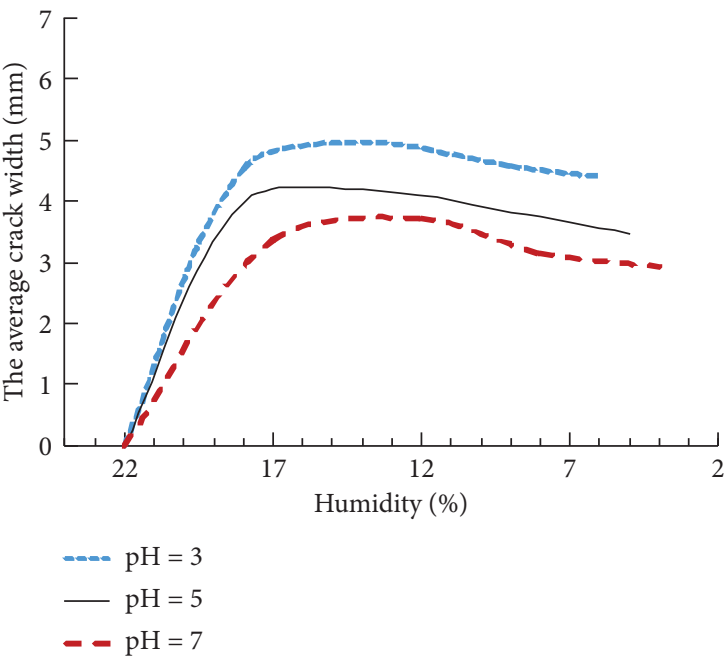

(a)

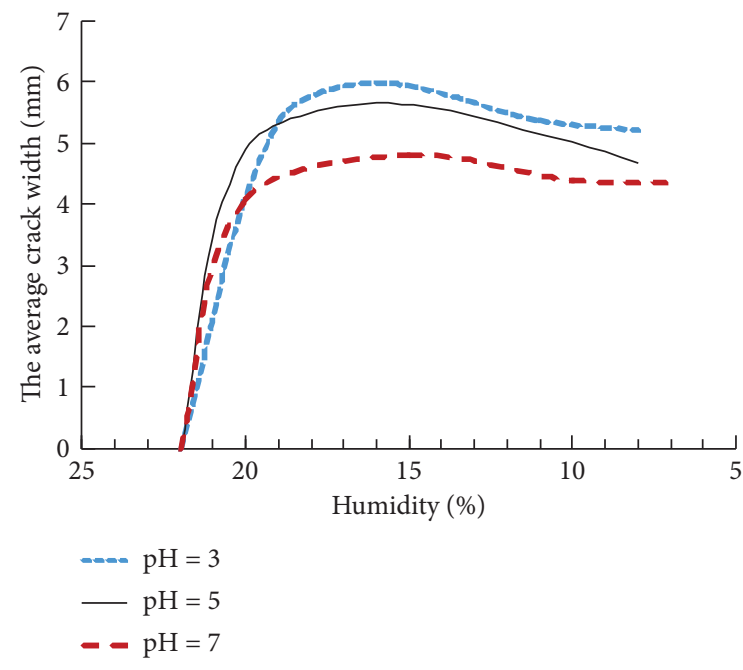

(b)

FIGURE 8: The average crack width under cyclic drying-wetting samples during the dehumidification process. (a) One-time cyclic dryingwetting. (b) Four-times cyclic drying-wetting.

3.6.2. The Influence Mechanism of Acid Rain and DryingWetting Cycle on Crack Development of Expansive Soil. The forces between soil particles can be mainly divided into interparticle attraction and repulsion force [24]. The interparticle attraction consists of electrostatic force, magnetic force, molecular force, capillary force, and chemical cementation force. The interparticle repulsion force includes electrostatic repulsion force and repulsion force generated by the interaction of electric double layers. The interaction of gravity and repulsion controls the arrangement of soil particles and thus affects the structural stability of the soil. Under the joint action of acid rain and dryingwetting cycle, the cementitious material in the expansive soil will be washed away rapidly, resulting in the decrease of chemical cementation force and soil particle weight. The electrostatic attraction is mainly produced by the mutual attraction between the negatively charged clay particles in the polymer and the cations in the cement. Both the decrease of the cementing material and the increase of the distance between the aggregates weaken the electrostatic attraction. At the same time, the pore water pressure will be increased due to the increase of pores in the microstructure. As a result, the repulsion force between the aggregates exceeds the gravitational force, which breaks the force equilibrium between soil water electrolytes, resulting in the formation of new pores. 


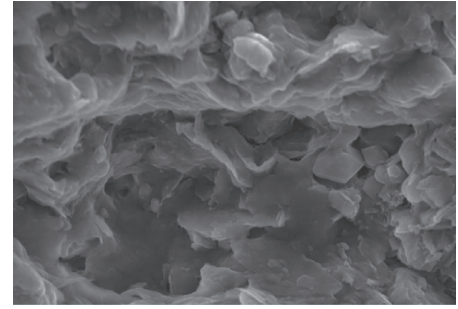

(a)

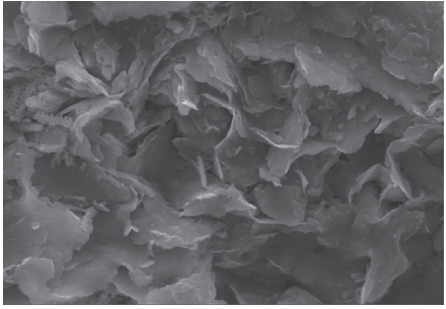

(b)

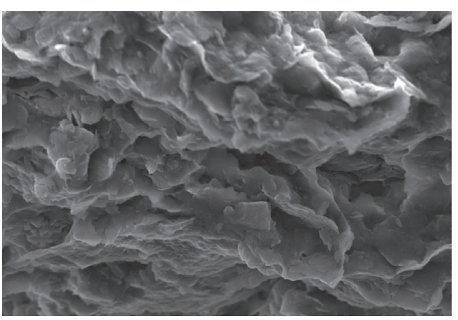

(c)

FIGURE 9: Crack development of sample with different $\mathrm{pH}$ value solution after one-time cyclic drying-wetting $(5000$ times larger). (a) $\mathrm{pH}=7$, (b) $\mathrm{pH}=5$, and (c) $\mathrm{pH}=3$.

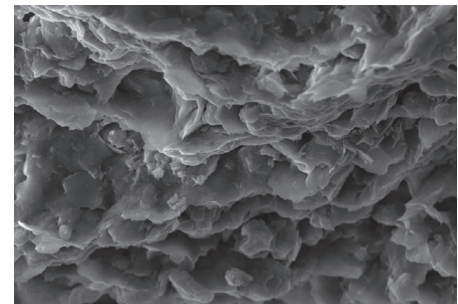

(a)

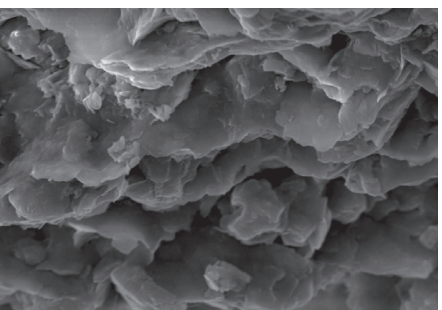

(b)

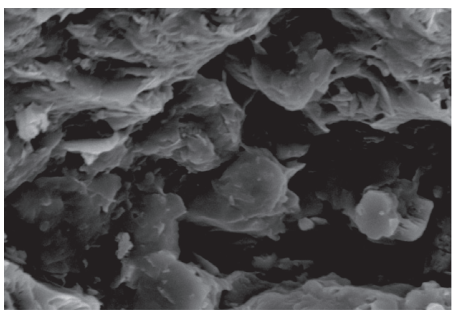

(c)

Figure 10: Crack development of the sample with different $\mathrm{pH}$ values' solution after four-time cyclic drying-wetting (5000 times larger). (a) $\mathrm{pH}=7$, (b) $\mathrm{pH}=5$, and (c) $\mathrm{pH}=3$.

TABle 7: Main chemical composition and content of Baise expansive soil.

\begin{tabular}{|c|c|c|c|c|c|c|c|}
\hline \multirow{3}{*}{ Main chemistry component } & \multicolumn{7}{|c|}{ Mass percentage (\%) } \\
\hline & \multirow{2}{*}{ Undisturbed sample } & \multicolumn{3}{|c|}{ One-time cyclic drying-wetting } & \multicolumn{3}{|c|}{ Four-time cyclic drying-wetting } \\
\hline & & $\mathrm{pH}=7$ & $\mathrm{pH}=5$ & $\mathrm{pH}=3$ & $\mathrm{pH}=7$ & $\mathrm{pH}=5$ & $\mathrm{pH}=3$ \\
\hline $\mathrm{SiO}_{2}$ & 46.98 & 51.96 & 52.24 & 53.15 & 53.957 & 54.887 & 55.063 \\
\hline $\mathrm{Al}_{2} \mathrm{O}_{3}$ & 18.04 & 19.89 & 20.01 & 20.64 & 20.89 & 20.509 & 21.173 \\
\hline $\mathrm{CaO}$ & 12.69 & 10.27 & 8.96 & 5.74 & 6.155 & 3.836 & 1.831 \\
\hline $\mathrm{Fe}_{2} \mathrm{O}_{3}$ & 7.96 & 7.31 & 6.84 & 5.02 & 6.142 & 5.771 & 3.929 \\
\hline $\mathrm{K}_{2} \mathrm{O}$ & 3.26 & 3.19 & 2.99 & 2.22 & 3.113 & 2.657 & 1.341 \\
\hline
\end{tabular}

Lamellar microstructure unit

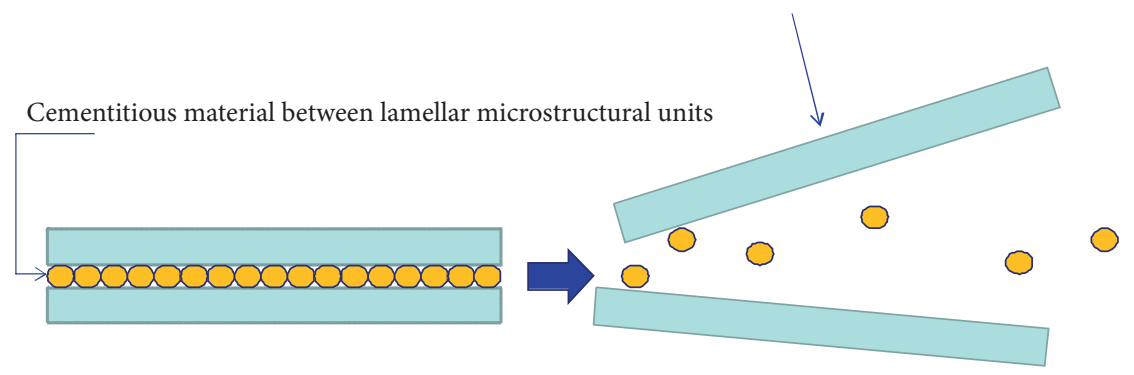

(a) Surface-to-surface contact

(b) Edge-to-edge contact

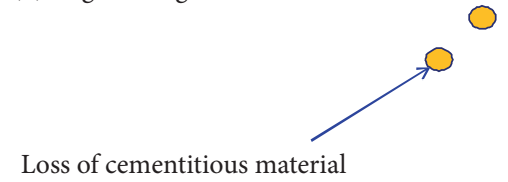

FIGURE 11: Structure model of lamellar microstructure unit of Baise expansive soil. 
In addition, the dehumidification process in the acidic environment accelerates the evaporation of the moisture in the expansive soil [22]. As the new pores expand from the surface to the inside, the moisture is distributed more unevenly in the soil structure. Under many unfavorable conditions, the stress condition of the soil in the sample was changed to tension at the top and compression at the bottom. Once the upper tensile stress exceeds the tensile strength of the soil block [25], the inner cracks appear and develop gradually.

\section{Conclusion}

(1) Acid rain aggravates the swelling deformation of expansive soil and promotes the development of crack. Moreover, the stronger the acidity of the rain, the more severe the swelling and development of crack.

(2) The interaction of acid rain and drying-wetting cycles promotes the swelling deformation and crack development of Baise expansive soils more significantly as compared with the neutral rainwater and drying-wetting cycles.

(3) The acid rain corroded the binding materials in Baise expansive soil and weakened the structural connection strength, thereby resulting in continuous increases in the size and number of microvoids. Besides, the drying-wetting cycles deteriorate the above process.

(4) The swell-shrink and cracking characteristic is one of the three typical characteristics of expansive soil. The interaction of acid rain and drying-wetting cycles promotes the development of crack and swelling deformation of expansive soil, which is extremely unfavorable to the stability of cutting slope.

\section{Data Availability}

Most of the data are available in the article. If the underlying data are needed, they will be provided later.

\section{Conflicts of Interest}

The authors declare that there are no conflicts of interest regarding the publication of this paper.

\section{Acknowledgments}

This research was financially supported by the National Key R\&D Program of China (Grant no. 2019YFC1509800) and the Scientific Research Project of the Education Department of Hunan Province (Grants nos. 19A044, 19C0152, and 19C0167).

\section{References}

[1] C. G. Bao, "Behavior of unsaturated soil and stability of expansive soil slope," Journal of Geotechnical Engineering, vol. 26, no. 1, pp. 1-15, 2004.

[2] Z. G. Yin and B. Xu, "Slope stability of expansive soil under fissure influence," Journal of Geotechnical Engineering, vol. 33, no. 3, p. 454, 2011.
[3] X. W. Li, G. Z. Dai, C. Y. Yu et al., "Stability analysis of cut slope of expansive soil based on fissure description," Journal of Geotechnical Engineering, vol. 35, no. 6, pp. 1069-1075, 2013.

[4] Z. M. He, D. Xiang, Y. X. Liu et al., "Deformation behavior of coarse-grained soil as an embankment filler under cyclic loading," Advances in Civil Engineering, vol. 2020, Article ID 4629105, 13 pages, 2020.

[5] P. Yang, X. Y. Tang, X. Z. Wang et al., "Shear strength of expansive soils under wet-dry cycles with loading," Geotechnical Mechanics, vol. 39, no. 7, pp. 2311-2317, 2018.

[6] M. Jalali and E. Naderi, "The impact of acid rain on phosphorus leaching from a sandy loam calcareous soil of western Iran," Environmental Earth Sciences, vol. 66, no. 1, pp. 311-317, 2011.

[7] R. Moore and D. Brunsden, "Physico-chemical effects on the behaviour of a coastal mudslide," Géotechnique, vol. 46, no. 2, pp. 259-278, 1996.

[8] M. Jaboyedoff, F. Baillifard, E. Bardou, and F. Girod, "The effect of weathering on alpine rock instability," Quarterly Journal of Engineering Geology and Hydrogeology, vol. 37, no. 2, pp. 95-103, 2004.

[9] X. R. Liu, D. L. Li, Z. Wang et al., "The effect of dry-wet cycles with acidic wetting fluid on strength deterioration of shaly sandstone," Chinese Journal of Rock Mechanics and Engineering, vol. 35, no. 8, pp. 1543-1554, 2016.

[10] X. R. Liu, W. Yuan, Y. Fu et al., "Deterioration rules of shear strength in sandstones under wetting and drying cycles in acid and alkali environment," Chinese Journal of Geotechnical Engineering, vol. 39, no. 12, pp. 2320-2326, 2017.

[11] C. R. V. Prasad, P. H. P. Reddy, V. R. Murthy et al., "Swelling characteristics of soils subjected to acid contamination," Soils \& Foundations, vol. 58, no. 1, pp. 110-121, 2017.

[12] H. D. Gu and X. Gu, "Effect of acid rain on engineering properties of light-weight soils," Environmental Science and Technology, vol. 29, no. 3, pp. 17-18, 2006.

[13] Z. Bakhshipour, A. Asadi, A. Sridharan et al., "Acid rain intrusion effects on the compressibility behaviour of residual soils," Journal of Environmental Geotechnics, vol. 6, pp. 1-38, 2017.

[14] Z. Bakhshipour, A. Asadi, B. B. K. Huat, A. Sridharan, and S. Kawasaki, "Effect of acid rain on geotechnical properties of residual soils," Soils and Foundations, vol. 56, no. 6, pp. 1008-1020, 2016.

[15] Z. Bakhshipour, A. Asadi, B. B. K. Huat et al., "Long-term intruding effects of acid rain on engineering properties of primary and secondary kaolinite clays," International Journal of Geosynthetics and Ground Engineering, vol. 2, no. 3, p. 21, 2016.

[16] G. Sarkar, M. R. Islam, M. Alamgir et al., "Effect of acid rain on geotechnical properties of composite fine-grained soil," International Journal of Applied Science \& Engineering Research, vol. 1, no. 1, pp. 64-73, 2012.

[17] S. Z. Zhu, "The effect of acid rain in Liuzhou on the physical and mechanical properties of soil," Journal of Guilin Institute of Technology, vol. 016, no. 02, pp. 143-149, 1996.

[18] J. Chang, H. P. Yang, J. Xiao et al., "Effects of acid rain infiltration on shear strength of expansive soils and microscopic tests," Journal of Central South University (Natural Science Edition), vol. 50, no. 01, pp. 206-213, 2019.

[19] A. Sun, X. C. Li, S. Yu et al., "Study on source-sink effect in the process of carbonate rock dissolved by acid rain: an example of typical karst regions in Guangxi," Carsologica Sinic, vol. 36, no. 1, pp. 101-108, 2017. 
[20] A. Z. Cheng, H. H. Wei, and F. Tan, "Analysis of the temporalspatial distribution and seasonal variation of the acid rain in Guangxi Province," Meteorological and Environmental Research, vol. 1, no. 1, pp. 62-65, 2010.

[21] X. M. Zhang, F. H. Chai, S. L. Wang et al., "Current situation of acid rain research in China," Environmental Science Research, vol. 23, no. 05, pp. 527-532, 2010.

[22] H. P. Chang, J. Yang, J. Xiao et al., "Effect of acid environment on swelling-shrinkage performance of Baise expansive soil and its microscopic interpretation," Journal of Transportation Engineering, vol. 19, no. 01, pp. 24-32, 2019.

[23] Y.-H. Wang and W.-K. Siu, "Structure characteristics and mechanical properties of kaolinite soils. II. Effects of structure on mechanical properties," Canadian Geotechnical Journal, vol. 43, no. 6, pp. 601-617, 2006.

[24] K. James, G. R. Gao, X. J. Han, and X. H. Zhang, Principle of Geotechnical Engineering and Soil Property Analysis, Nanjing Institute of Technology Press, Nanjing, China, 1988.

[25] J. Zhang, B. W. Gong, B. Hu et al., "Study of evolution law of fissures of expansive clay under wetting and drying cycles," Geotechnical Mechanics, vol. 32, no. 9, pp. 2729-2734, 2011. 